\title{
Multidisciplinary investigations on the Roman aqueduct of Grumentum (Basilicata, Southern Italy)
}

\author{
Massimo Bavusi $\left({ }^{1}\right)$, Domenico Chianese $\left({ }^{3}\right)$, Salvatore Ivo Giano $\left({ }^{2}\right)$ and Marco Mucciarelli $\left({ }^{2}\right)$ \\ $\left.{ }^{1}{ }^{1}\right)$ Università degli Studi della Basilicata, Potenza, Italy \\ ${ }^{(2)}$ DiSGG, Università degli Studi della Basilicata, Potenza, Italy \\ $\left(^{3}\right)$ Istituto di Metodologie per l'Analisi Ambientale (IMAA) - CNR, Tito Scalo (PZ), Italy
}

\begin{abstract}
The Romans built the ancient town of Grumentum during the 3rd century B.C. in the southern part of the Agri high Valley (Basilicata Region, Southern Italy) near the confluence of the Sciaura stream in the Agri River. Now it is one of the most important archaeological sites of Southern Italy. In fact, after a period of wars in this area between Romans and Carthaginians, a great deal of restoration was started in 57 B.C. These works affected the city walls, public buildings and finally endowed the Roman colony with important infrastructures, such as the new aqueduct. In this work, we attempt to reconstruct the ancient layout of the Roman aqueduct of Grumentum. As a starting point, we followed some descriptions from the 19th century, when the structure was still well preserved. Then, we performed a multidisciplinary geophysical approach to the best preserved remains of the aqueduct. In particular, the geophysical investigation started with the use of a portable GPS allowing us to acquire the co-ordinates of the outcropping rests of the ancient structure. Then, we used an optical pumping magnetometer to perform seven gradiometric maps over a broad area of about $8000 \mathrm{~m}^{2}$. From the literature descriptions, dating to the first part of the 19th century, we can deduce that the state of preservation of the Roman aqueduct was much better than the present one. Thus we can hypothesise as the cause of its fast involution the fact that it was located in the epicentral area of the large destructive earthquake which occurred in the Basilicata Region in 1857 (Mallet, 1862). To this aim, we performed a first attempt to correlate the state of preservation of the aqueduct remains with the local seismic amplification by means of the HVSR (Horizontal to Vertical Spectral Ratio) technique. This survey allowed us to obtain the site amplification spectra along the aqueduct layout and assess the fundamental vibration frequency of the investigated structure. The possibility of landslides was ruled out by a careful geological survey. The relationship between aqueduct path and damage should then be attributed to closeness to earthquake seismogenic fault.
\end{abstract}

Key words geoarchaeology-magnetic prospecting HVSR investigation - seismogenic fault - Southern Italy

Mailing address: Dr. Salvatore Ivo Giano, DiSGG, Università degli Studi della Basilicata, Viale dell'Ateneo Lucano 10, 85100 Potenza, Italy; e-mail: giano@unibas.it

\section{Introduction}

During the last few years, there has been an increasing interest in the application of high resolution geophysical methods for the reconstruction of the subsoil geometry of sites located in areas of environmental or archaeological interest (Chavez et al., 2001; Ates, 2002). The main strategy adopted by most researchers involves the integrated use of different geophysical methodologies (Hesse, 1999), such as 
electrical and magnetic techniques (Cammarano et al., 1997; Witten et al., 2000; Sarris et al., 2002; Abdallatif et al., 2003) or seismic and magnetic techniques (Hildebrand et al., 2002) to obtain detailed information based on objective statistical criteria on the presence of buried bodies.

In this work we will show the main results of a multidisciplinary investigation carried out along the partly supposed path of the roman aqueduct of Grumentum, located in the Basilicata Region, Southern Italy, built during the 1st century B.C.

The main aim of our research is to locate the aqueduct path, both following the descriptions provided by many authors in the past (Lombardi, 1836) and referring to some outcropping rests preserved until the present day. Furthermore, we attempted to disclose possible correspondences existing between the state of preservation of the investigated structure and the earthquake which occurred in the Basilicata area in 1857 (Mallet, 1862), i.e. possible dislocations along the path.

Starting from these objectives, we divided our work into four main steps:

1) A detailed geological survey to investigate the foundation soil looking for inhomogeneities and soil instabilities along the aqueduct path.

2) Location of the aqueduct outcropping remains by means of a portable GPS receiver to delimit the study area and identify a possible large scale bending.

3) Reconstruction of the Roman aqueduct layout by means of a high resolution magnetometric survey; in particular, we employed a high sensitivity optical pumping magnetometer in gradiometric mode: this configuration, in fact, allows us to acquire a great deal of natural magnetic field data with a very high resolution thanks to its handiness and easy-to-use features.

4) Research of permanent deformations in the aqueduct, to identify a possible correlation with historical earthquakes in the investigated area. To this aim, we also attempted to quantify the local seismic response along the aqueduct path by means of measures of microtremors, performed using the HVSR technique.

\subsection{Location of the Roman aqueduct}

The ancient Roman aqueduct was located in the southern part of the Agri Valley in the Basilicata Region (fig. 1). It collected the water coming from Moliterno and then, after a large curve, it passed through Sarconi, crossing the Sciaura stream by means of a bridge. It went on in the NE direction, and then changed its direction before entering the town (Giardino, 1983). Finally, it went through the Grumentum town, in the $\mathrm{N}$ direction, following a path whose few fragments are still preserved today.

\subsection{Geological and geomorphological setting}

The high valley of the Agri River is a NWSE trending Quaternary intermontane basin of the Southern Apennines that includes in its southernmost zone the Grumento plain. The genesis and the Early Pleistocene evolution of the basin were controlled by left-lateral strikeslip $\mathrm{N} 120^{\circ}$ trending master faults, reactivated as normal faults since Middle Pleistocene to Holocene times (Di Niro and Giano, 1995; Schiattarella et al., 1998; Giano et al., 2000). Tectonics has strongly controlled the shape, morphology and sedimentary evolution of the basin up to the present as demonstrated by active tectonics and historical seismicity of the area (cf. Mallet, 1862; Amato and Selvaggi, 1993; Giano et al., 2000).

The Quaternary sediments outcropping in the study area are entirely constituted of continental clastic successions, represented by Upper Pleistocene slope coarse-grained deposits. They form coalescent talus cones distributed along the piedmont of the valley floor and by Middle to Upper Pleistocene alluvial deposits («Complesso Val d'Agri»; Di Niro et al., 1992) in the plain. The latter is divided into six main intervals, shown in fig. 1. Two different lithofacies are recognised: the first, just outcropping in the talweg of the Sciaura stream, is composed of brownish-grey silty clay and silt (fluvial-lacustrine and overbank deposits); the second, outcropping in the entire study area, is constituted by an alternation of gravel, silty sand and silt with interbedded conglomerates (alluvial 


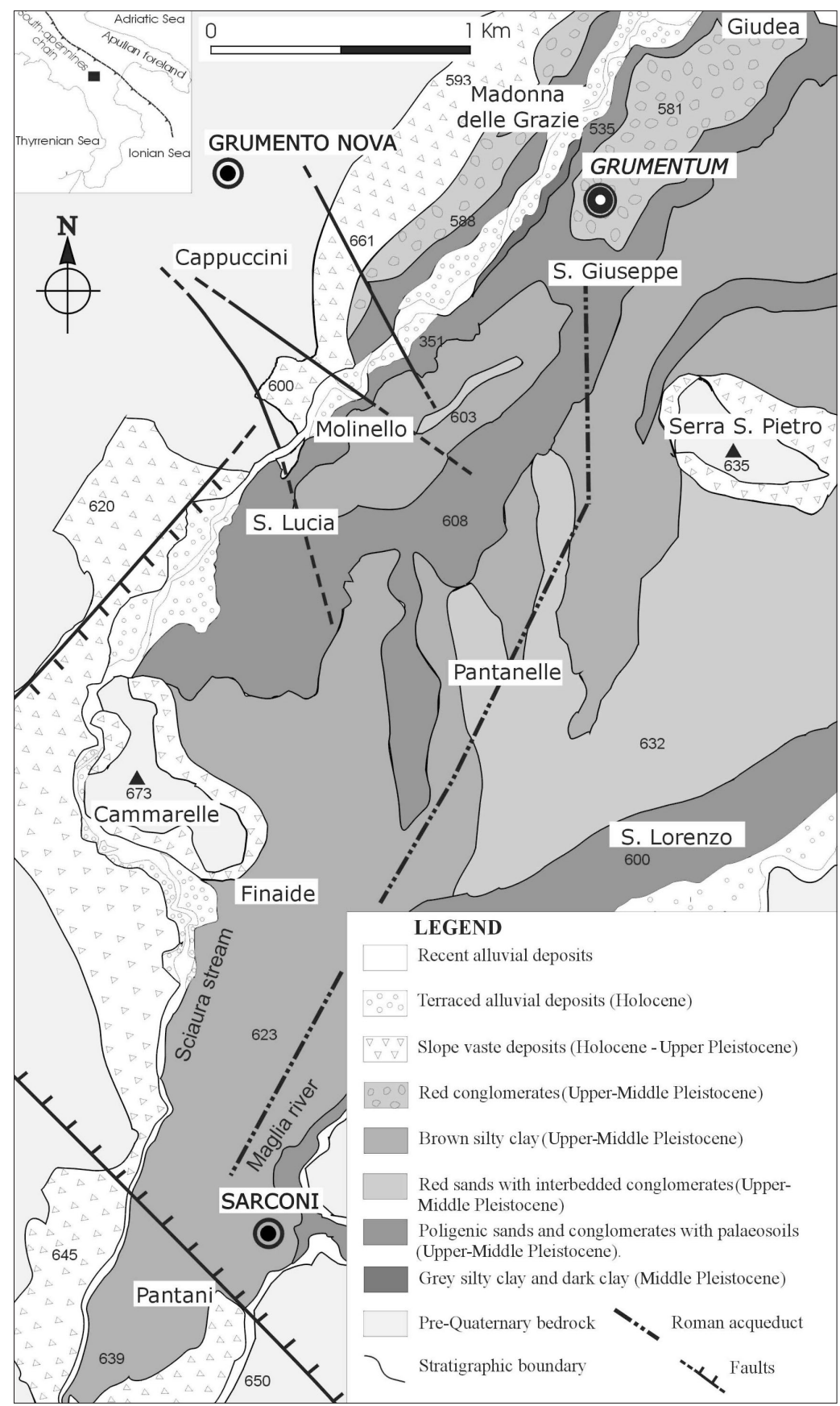

Fig. 1. Geological map of the investigated area, with location of the ancient layout of the Roman aqueduct in Grumentum, as derived from literature depictions and on the basis of a few fragments preserved today. 
plain and alluvial fans deposits), and by massive polygenic coarse-grained conglomerates (alluvial fans deposits).

The depositional top of the alluvial succession of the «Complesso Val d'Agri» was dissected and terraced by Sciaura, Vella and Maglia streams in the Grumento plain during Late Pleistocene. Lastly, the Holocene evolution of the area is testified by several orders of recent stream terraces embedded in the depositional top terrace of the Grumento plain.

Some morphostructural elements NW-SE and NE-SW trending are recognized in the carbonate hills of the Grumento Nova town and confirmed by anomalies in the network drainage of the Sciaura stream.

The depositional top terrace of the Grumento plain in historical age constituted a natural plateau for Roman colonization and a easily link road for the Vallo di Diano area and Metaponto plain. These reasons explain the origin of Grumentum town in the first part of the 3rd Century B.C. In later times the same indigenous (Lucanian) peoples have induced a «self-Romanization» process of the area (Bottini, 1989).

The area around the supposed aqueduct path was also investigated to check for the presence of landslides or other instabilities. The gentle slopes along the aqueduct path rule out the possibility of instability phenomena.

\section{GPS acquisition}

GPS (acronym for Global Positioning System) technology represents one of the most powerful tools for modern geophysical investigation because it provides accurate locations of the surveys and compares the anomalous patterns found by the different geophysical methods. Furthermore, with real-time or post-processing differential correction, positions can be located or mapped with sub metre or better accuracy (Kvamme, 1999; Barratt et al., 2000; Harrower et al., 2002).

Along the ancient path of the Roman aqueduct many outcropping fragments are still present. Starting from this evidence, we acquired the latitude and longitude co-ordinates of the best preserved rests by means of a portable
Trimble GPS receiver. In particular, we acquired the latitude and longitude of 47 fragments along a profile of about $400 \mathrm{~m}$ and oriented in N-S direction near the National Archaeological Museum of Agri high Valley and a single fragment $2.5 \mathrm{~m}$ long oriented in a NESW direction (fig. 2).

In this way, we obtained a theoretical reconstruction of the original direction of the Roman aqueduct, in perfect agreement with the direction of an ancient Roman road described in literature (Giardino, 1983). It is worth noting that close to the point where the remains disappear, they show a bend. The deviation is of the order of 1-2 $\mathrm{m}$ from the straight path that was the obvious one for Roman engineers.

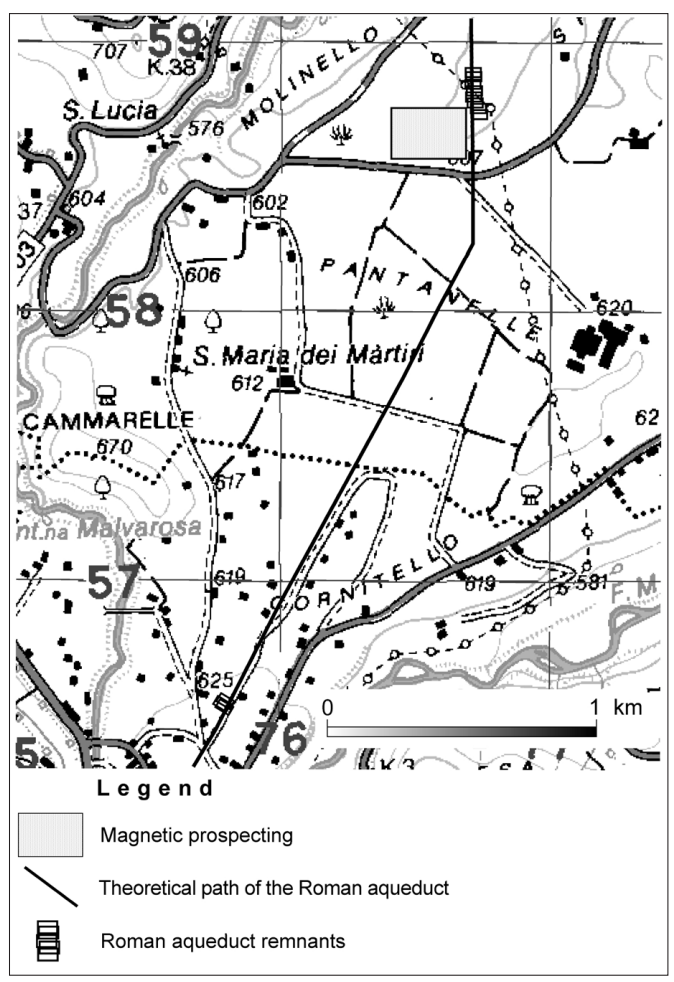

Fig. 2. Location of the outcropping remains of the ancient structure. The theoretical direction of the ancient Roman aqueduct is evidenced by two segments, oriented in N-S and NE-SW directions, respectively. 


\section{Magnetic investigation}

For the magnetic prospecting we used a caesium vapour magnetometer G-858 GEOMETRICS in gradiometric configuration, with the two magnetic sensors set in a vertical direction at a distance of about $1 \mathrm{~m}$ apart. In fact, surveys where the maximum accuracy is desired require diurnal correction from a base station installed close to the survey area, but generally the use of the gradiometric configuration allows us to subtract the diurnal effect from the magnetic maps automatically (Sharma, 1997).

The G-858 magnetometer includes some unique features, intended to assist the collection of magnetic data; first, the system visualizes the survey area beforehand, entering in the desired survey location points; then, it reviews both the locations and the data during the survey; finally, the unit edits data, both in the field and in later processing.

By means of this magnetometer, we acquired two test maps across the best preserved fragments and, successively, seven maps covering a broad area of about $8000 \mathrm{~m}^{2}$.

Among the various modes provided by the magnetic sensors, we selected the mapped survey mode that allows us to specify and visualize the survey area and to move around within the investigated area in a non-continuous fashion by means of regular grids with sampling step 1 $\mathrm{m}$ spaced and sampling rate of $10 \mathrm{~Hz}$.

\subsection{Spikes removal}

The interpretation of the magnetic data collected in areas of cultural interest is very problematic, due to the anthropic noise, the small dimensions of the magnetic anomalies and the weak susceptibility contrast between the remains of the investigated structures and the ground that contains them. Many procedures have been proposed, especially to improve the signal-to-noise ratio (Brizzolari et al., 1992, 1993), such as the bidimensional cross-correlation technique (Brizzolari et al., 1993), making use of a proton precession magnetometer in gradiometric configuration.

Furthermore, isolated spikes can often be observed in the magnetic maps. Their origin can be ascribed mainly to the presence in the subsurface of metallic remains of various nature, such as containers and cables. Many models have been proposed to treat the spikes: the most common methods cited in literature to find and remove the spikes are the median filter (Tabbagh, 1999) and the GESD procedure (Ciminale and Loddo, 2001), which allows us to process the spikes as observations which appear to be inconsistent with the remainder of the data (Barnett and Lewis, 1984; Iglewicz and Hoaglin, 1993). Other methods are based on iterative procedures to identify these isolated values, selecting various thresholds and comparing the single values by means of the field data (Brizzolari et al., 1990). Ciminale and Loddo (2001) proposed a theory according to which the spikes present in the magnetic data can be considered extreme events with respect of the other magnetic values, and then they can be eliminated and subsequently substituted by employing robust statistical methodologies.

To this aim, we developed automatic software, named DESPIKE, written in Matlab programming language, for the detection, removal and replacement of the spikes. The main features of this software have been described in a previous paper (Chianese et al., 2004). This software allows us to simply clean the magnetic maps of the outliers due to the presence of troubles during field measurements and gives as a result that the spikes are no longer present, while the principal magnetic anomalies appear more clearly evident.

\subsection{Test maps}

We realised two test maps to check the magnetic response of the outcropping rests of the Roman aqueduct. The most interesting results were found in the first test map performed across a structure located in a wood and shows well defined anomaly oriented in the N-S direction, ten meters long, with magnetic values of about 25 nT/m (fig. 3). Furthermore, the presence of anomalous values of about $50 \mathrm{nT} / \mathrm{m}$ in the middle part of the map can be ascribed to lead fragments used as joints along the aqueduct path, as referred from the literature (Capano, 1999). 


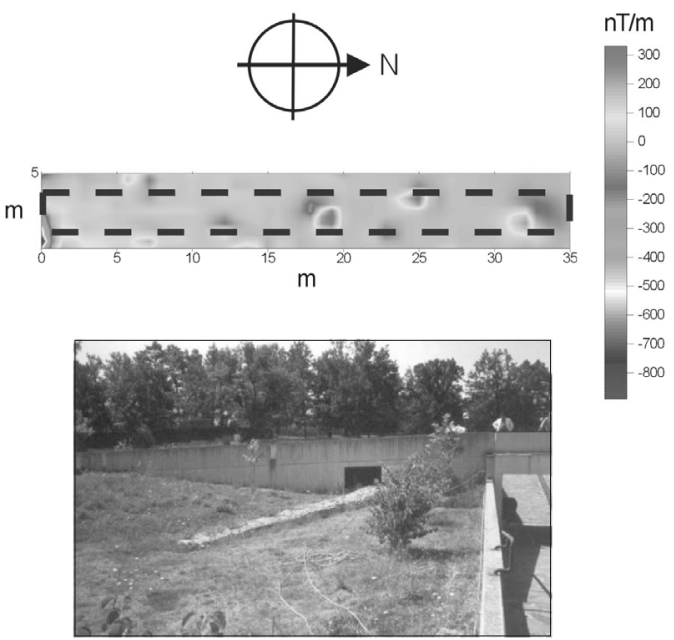

Fig. 3. First test map performed across a structure located in the woods, south of the museum of the Agri high Valley.

A second test map was performed near the Archaeological Museum of Agri high Valley, where the longest and best preserved fragment of the ancient structure is still present. Unfortunately, the presence of a reiforced concrete wall produced some spikes of about $700 \mathrm{nT} / \mathrm{m}$ that cover the magnetic evidence of the rests.

\subsection{Magnetic survey}

Because the excavation made by a gas company revealed a buried segment of the ancient plumbing (fig. 4), we chose to investigate the area immediately around this new finding, drawing seven magnetic maps covering a broad area of about $8000 \mathrm{~m}^{2}$. Now, we will show the main results of the magnetic survey performed over this area.

Starting from this new outcrop, a first magnetic map was drawn in a limited area $(30 \mathrm{~m}$ in the $x$ and $15 \mathrm{~m}$ in the $y$ directions, respectively) located in proximity of the excavation, to investigate the possible continuation of the aqueduct base. What we can observe in this map is a well defined rectangular structure, evidenced by the black line, oriented in an E-W direction, with magnetic intensity of about $15-20 \mathrm{nT} / \mathrm{m}$, compatible with the presence of buried buildings (fig. 5).

The most interesting results were observed in the third map $(25 \mathrm{~m}$ in the $x$ and $50 \mathrm{~m}$ in the $y$ directions, respectively) which shows a magnetic anomaly going through the area approximately in the E-W direction, with a magnetic intensity of about $20-30 \mathrm{nT} / \mathrm{m}$, similar to that of the test maps and with a shape and an extension compatible with the presence of the aqueduct foundation (fig. 6). Starting from this evidence, we decided to continue in the west direction to verify whether the magnetic anomaly continued.

In fact, we performed the total map of the investigated area, putting together the seven maps, filtering the data to remove the local noise effects due to small metallic objects in the subsoil, and conforming the various scales (fig. 7): what we can observe is that the local anomalies, found in the single magnetic maps, show a certain continuity with the next and in particular we note the great anomaly that goes throughout the area from NW to $\mathrm{SW}$, with magnetic intensity of about 20-30 nT/m, and that could be ascribed to the presence of the buried aqueduct foundation. This feature can also be noted in the magnetic map of the same area inferred by the bottom magnetic sensor.

Finally, we can observe how in these figures some other magnetic evidence appears which

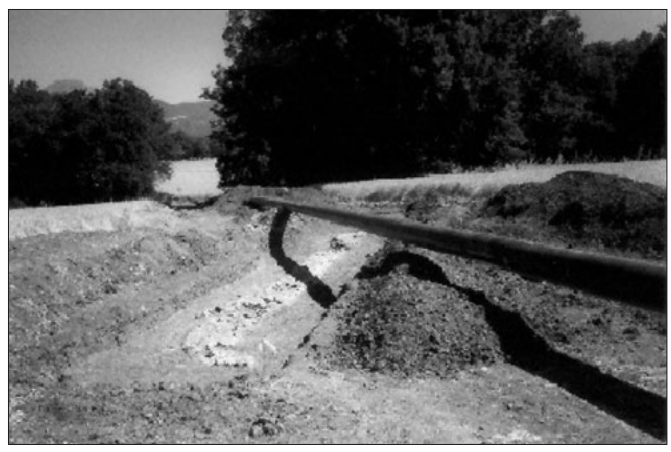

Fig. 4. Buried segment of the Roman aqueduct layout exposed by a gas company excavation. 


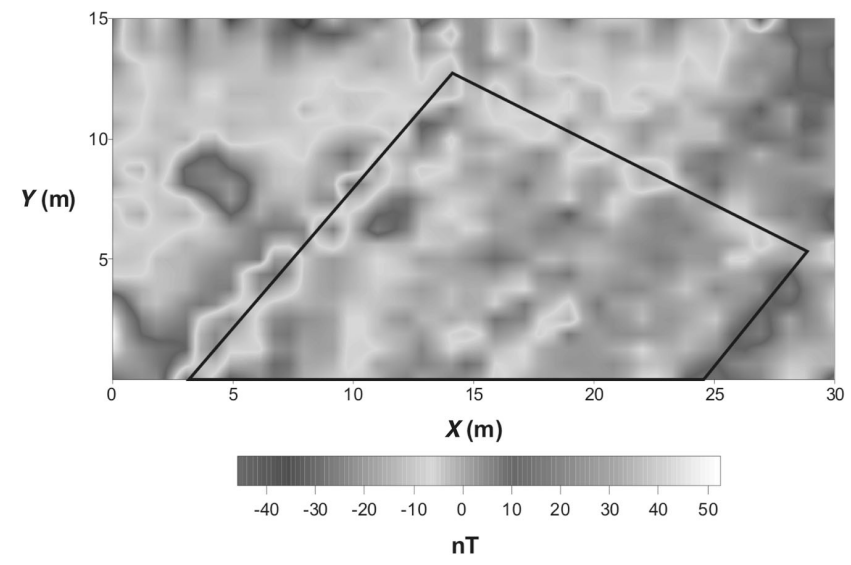

Fig. 5. Gradiometric map no. 1, performed near the excavation.
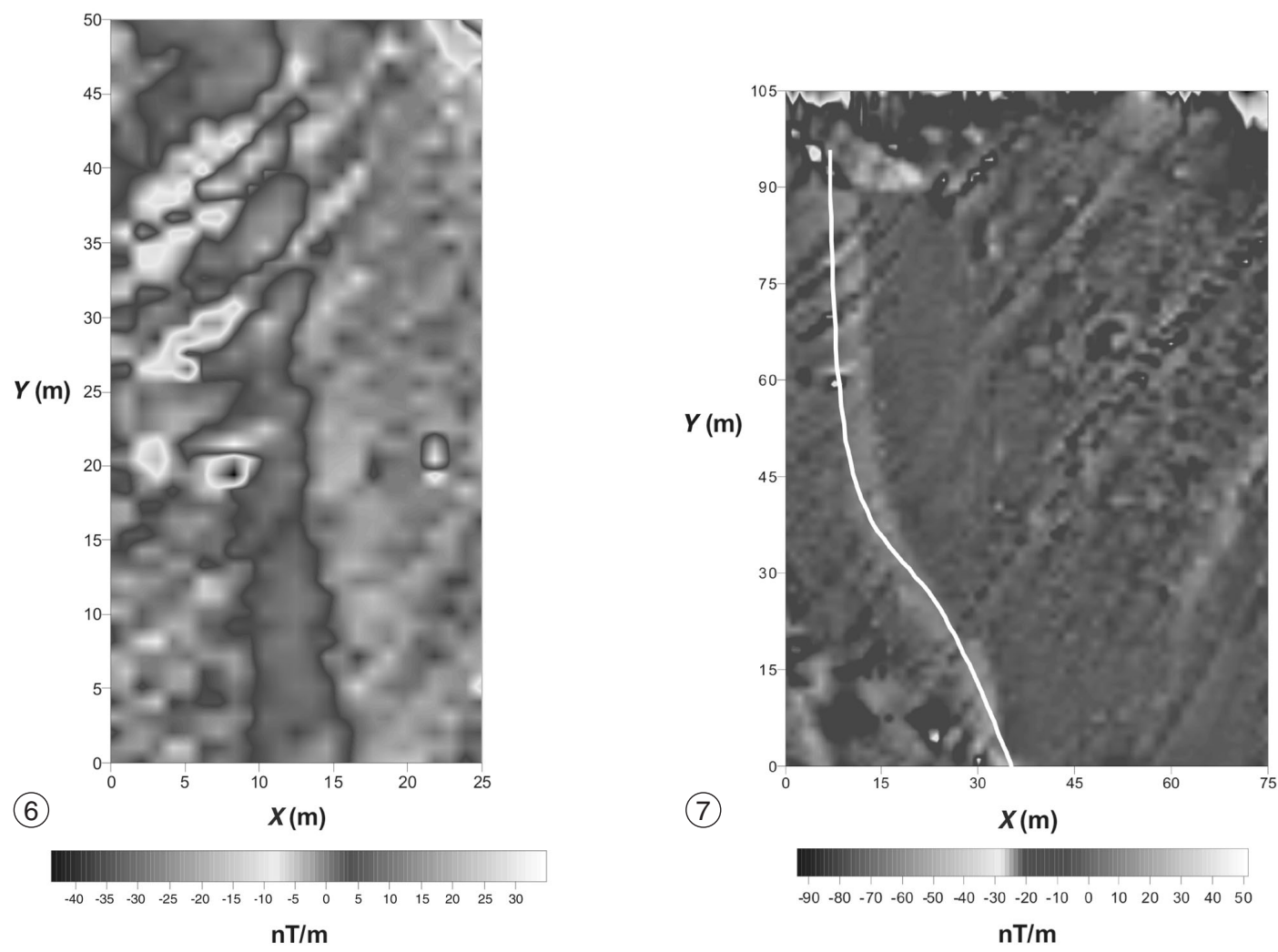

Fig. 6. Gradiometric map no. 2, showing a shape and extension compatible with the presence of the aqueduct foundation.

Fig. 7. Gradiometric map of the investigated area, obtained putting together seven maps. 
could be related to the presence of buried structures in the subsoil, especially for their direction. We did not consider them interesting because their magnetic intensity is not as high as the other and can be probably ascribed to the presence on the ground of furrows filled with stones and other materials.

\section{HVSR investigation}

We performed four seismic noise measurements (fig. 8), according to the Nakamura technique (Nakamura, 1989) to check if there was a correlation between the state of preservation of the remains and the site seismic amplification. The signals used were recorded with a tridirectional sensor Lennartz 3D-Lite (1 Hz period), connected with a 24 bit digital acquisition unit PRAXS-10 and a Pentium personal computer. The sensor has the same characteristics on the three axes.

The site transfer functions were computed in the following way. First of all, a set of at least five time series of $60 \mathrm{~s}$ each sampled at $125 \mathrm{~Hz}$ were recorded. Time series were corrected for the base-line and for anomalous trends, tapered with a cosine function to the first and last $5 \%$ of the signal and band-pass filtered from 0.1 to $20 \mathrm{~Hz}$, with cut off frequencies at 0.05 and $25 \mathrm{~Hz}$. Fast Fourier transforms were applied to compute spectra for 25 predefined values of frequency, equally spaced in a logarithmic scale between 0.1 and $20 \mathrm{~Hz}$, selected in order to preserve energy. The arithmetical average of all horizontal to vertical component ratios were taken to be the amplification function. Full details of the methodology and its limits are given by Mucciarelli (1998).

Figure 9 shows that there is no correlation between the conservation state of the aqueduct and the soil amplification. The arrow indicates the fundamental vibration frequency of one of the aqueduct remains, far from soil fundamental frequency. The area near the Archaeological Museum where the aqueduct is still best preserved shows the maximum amplification.

We then noticed that at this site there is a toppled section whose overturning can be dat-

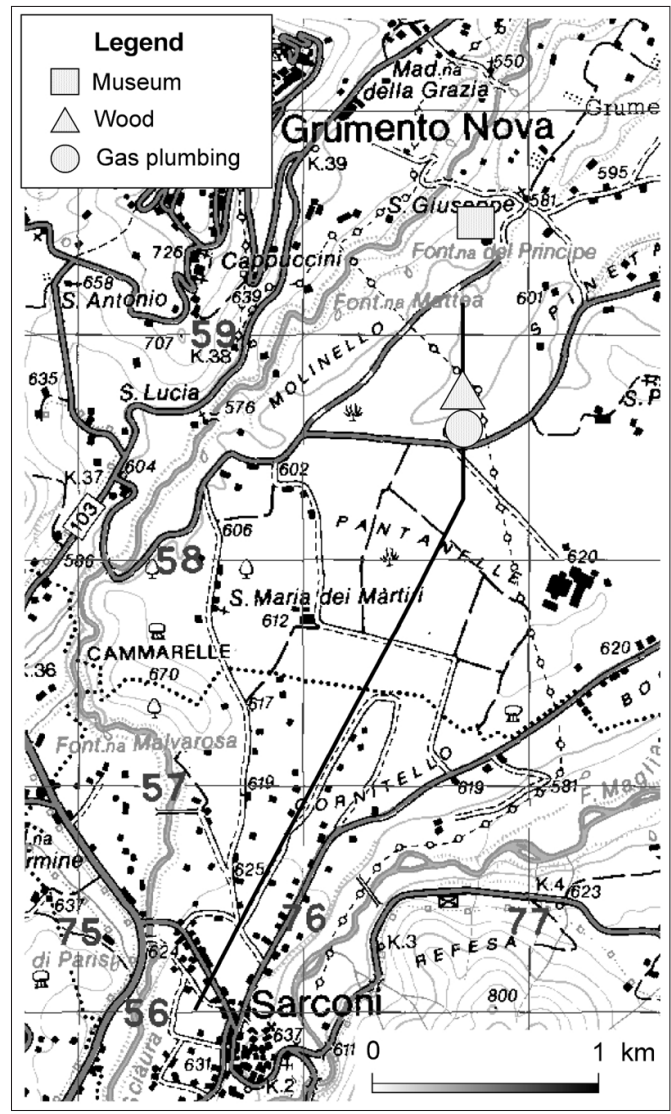

Fig. 8. Location of the noise measurements.

ed prior to 1940 thanks to the presence of trees on the top of the foundation (fig. 10). Moreover, GPS positioning reveals a slight eastward turn of the aqueduct's remains just before the section that disappeared. This section was still standing upright, according to some authors, at the beginning of 19 th century. Thus, it seems likely that the subsequent rapid ruin of the aqueduct was caused by the 1857 earthquake. The fact that soil amplification is not involved and that there are pieces of evidence concerning overturning and deviations may lead us to suppose that the aqueduct was in the epicentral area, possibly crossing a surface fault break. 


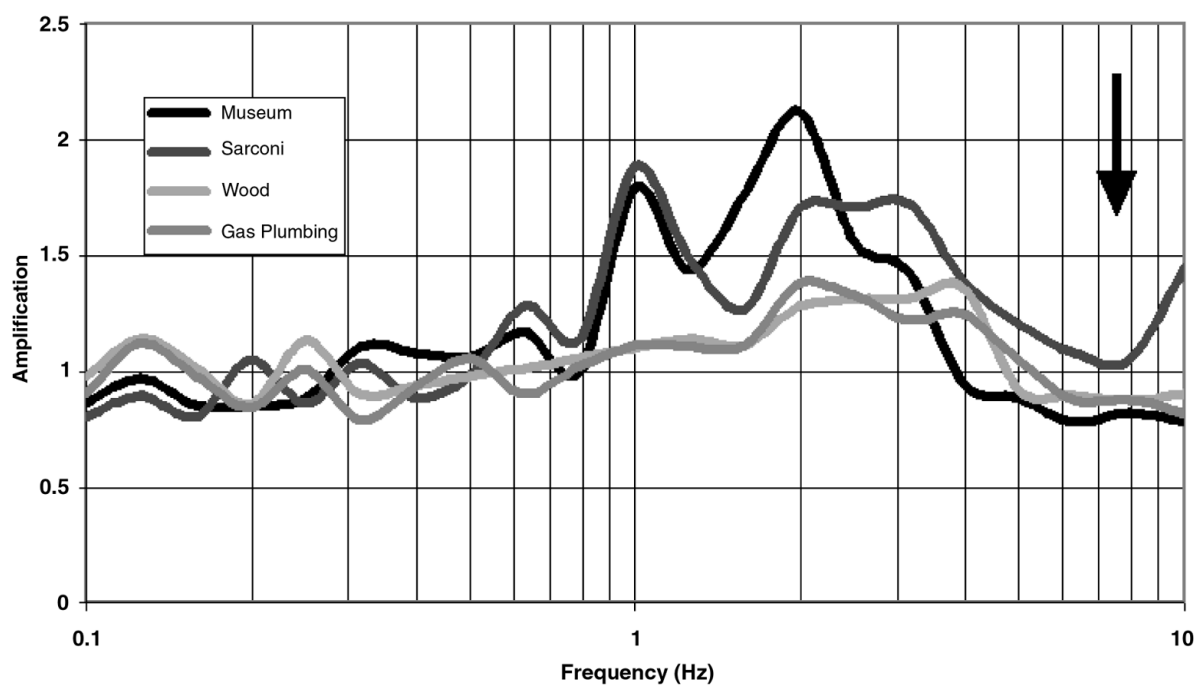

Fig. 9. Seismic amplification diagram showing that there is no correlation between the conservation state of the aqueduct and the soil amplification.

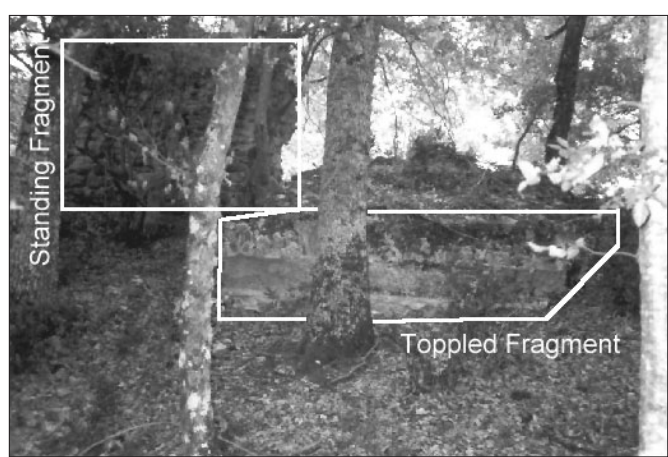

Fig. 10. Toppled fragment of the Roman aqueduct located in the woods, south of the museum of the Agri high Valley.

This is in agreement with the double fault plane solution proposed for the 1857 quake by Lizza (2000) and Bulfaro et al. (2002): the aqueduct could be crossing a transfer zone separating the two main faults involved in the earthquake.

\section{Conclusions}

We conducted a multidisciplinary investigation in a broad area in the south of the National Archaeological Museum of Agri high Valley, in the Basilicata Region, based on gradiometric measurements performed by means of an optical pumping magnetometer in gradiometric configuration and a seismic noise survey, by means of the Nakamura technique.

A new automatic filtering procedure to remove and replace the spikes present in the magnetic maps was developed, written in Matlab programming language.

From the magnetic survey we obtained seven gradiometric maps that revealed an ENEWSW trending structure, which can be related to the presence of the buried foundation of the Roman acqueduct, both for its dimensions and shape (fig. 7).

The fact that there is no correlation between the soil amplification and the state of preservation and that there are overturned rests and deviations from a straight path may suggest that the aqueduct was in the epicentral area of a seismic event, possibly crossing a surface fault 
break; the morphotectonic elements suggest a recent NW-SE trending fault zone.

\section{Ackowledgements}

Many thanks are due to the Soprintendenza ai Beni Archeologici della Basilicata for granting required permissions, and to the Director of the Museum and excavations in Grumentum, Dr. Capano.

\section{REFERENCES}

AbDallatiF, T.F. S.E. Mousa and A. Elbassiony (2003): Geophysical investigation for mapping the archaeological features at Qantir, Sharqyia, Egypt, Archaeol. Prospect., 10, 27-42.

Amato, A. and G. Selvaggi (1993): Aftershock location and $P$-velocity structure in the epicentral region of the 1980 Irpinia earthquake, Ann. Geofis., XXXVI (1), 3-15.

Ates, A. (2002): Archaeogeophysical investigations around the Bilge Qagan monument in Khosho Tsaidam, Mongolia, Archaeol. Prospect., 9, 23-33.

BARnetT, V. and T. LeWIS (1984): Outliers in Statistical Data (John Wiley \& Sons, New York).

Barratt, G., V. GAFFney, H. GoOdChild and S. Wilkes (2000): Survey at Wroxeter using carrier phase, differential GPS surveying techniques, Archaeol. Prospect., 7, 133-143.

BotTini, P. (1989): L'Alta Val d'Agri nell'Antichità (Soprintendenza archeologica della Basilicata, Lagonegro), pp. 76.

Brizzolari, E., E. Cardarelli, M. Feroci, S. Malagodi, S. Piro and L.Versino (1990): Analisi e pretrattamento di misure magnetiche differenziali effettuate con il metodo fluxgate, in Atti $9^{\circ}$ Conv. Ann. GNGTS, 13-15 Novembre 1990, Roma, 467-478.

Brizzolari, E., E. Cardarelli, M. Feroci, S. Piro and L. VERSino (1992): Magnetic survey in the Selinunte archaeological park, Boll. Geofis. Teor. Appl., 34, 157-168.

Brizzolari, E., E. Cardarelli, S. Piro and L. Versino (1993): Detection of subsurface magnetic anomalies of archaeological interest: computation of three-dimensional magnetic anomalies and interpretation using bidimensional cross-correlation, Geophys. Explor. Archaeol. Sites, 7, 3-16.

Bulfaro, M. C. Lizza, M. Mucciarelli, R. Caputo, M. Schiattarella and C. Nostro (2002): Geophysical investigation on the seismogenic source of the 1857 Earthquake in Agri Valley, Italy, in XVIII ESC General Assembly, Genova, vol. abstracts, p. 200.

Cammarano, F., P. Mauriello and S. Piro (1997): Highresolution geophysical prospecting with integrated methods. The ancient acropolis of Veio (Roma, Italy). Archaeol. Prospect., 4, 157-164.

CAPANO, A. (1999): Archeologia dell'Acqua in Basilicata (Sopraintendenza Archeologica della Basilicata), pp. 192.
Chavez, R.E., M.E. Camara, A. Tejero, L. Barba and L. MANZANILla (2001): Site characterization by geophysical methods in the archaeological zone of Teotihuacan, Mexico, J. Archaeol. Sci., 28, 1265-1276.

Chianese, D., M. D’Emilio, S. Di Salvia, V. Lapenna, M. RAgosta and E. Rizzo (2004): Magnetic mapping, ground penetrating radar surveys and magnetic susceptibility measurements for the study of the archaeological site of Serra di Vaglio (Southern Italy), J. Archaeol. Sci., 31, 633-643.

Ciminale, M. and M. Loddo (2001): Aspects of magnetic data processing, Archaeol. Prospect., 8, 239-246.

Di NiRO, A. and S.I. Giano (1995): Evoluzione geomorfologica del bordo orientale dell'Alta Val d'Agri (Basilicata), Studi Geologici Camerti, 1995/2, 207-218.

Di Niro, A., S.I. Giano and N. Santangelo (1992): Primi dati sull'evoluzione geomorfologica e sedimentaria del bacino dell'Alta Val d'Agri (Basilicata), Studi Geologici Camerti, 1992/1, 257-263.

Giano, S.I., L. Maschio, M. Alessio, L. Ferranti, S. ImPROTA and M. SCHIATTARELLA (2000): Radiocarbon dating of active faulting in the Agri high valley, Southern Italy, J. Geodyn., 29, 371-386.

Giardino, L. (1983): La Viabilità nel Territorio di Grumentum in Età Repubblicana ed Imperiale. Studi in Onore di Dinu Adamesteanu (Congedo Ed.), 207-217.

Harrower, M., J. McCorriston J. and E.A. OChes (2002): Mapping the roots of agriculture in Southern Arabia: the application of satellite remote sensing, global positioning system and geographic information system technologies, Archaeol. Prospect., 9, 35-42.

Hesse, A. (1999): Multi-parametric survey for archaeology: how and why, or why and why not?, J. Appl. Geophys., 41, 157-168.

Hildebrand, J.A., S.M. Wiggins, C. Henkart and L.B. CONYERS (2002): Comparison of seismic reflection and ground-penetrating radar imaging at the controlled archaeological test site, Champaign, Illinois, Archaeol. Prospect., 9, 9-21.

Iglewicz, D.M. and D.C. Hoaglin (1993): How to Detect and Handle Outliers (ASQ Press, Milwaukee), pp. 87.

KvammE, K.L. (1999): Recent directions and developments in geographical information systems, J. Archaeol. Res., 7, 153-201.

LizzA, C. (2000); Indagini geofisiche sul Terremoto del 1857 in Val d'Agri, Geological Sciences Graduate Thesis (Università degli Studi della Basilicata).

Lombardi, A. (1836): La Corona di Critonio (Osanna Ed., Venosa), pp. 108.

MALLET, R. (1862): Great Neapolitan Earthquake of 1857 (Chapman and Hill, London), 2 vols.

MucCIARELli, M. (1998): Reliability and applicability range of the Nakamura's technique, J. Earthquake Eng., 2, 1-14.

NAKAMURA, Y. (1989): A method for dynamic characteristics estimation of subsurface using microtremor on the ground surface, QR Railway Tech. Res. Inst., 30, 25-33.

Sarris, A., E. Athanassopoulou, A. Doulgeri-IntzesSILOGLOU, Eu. SKAFIDA and J. Weymouth (2002): Geophysical prospection survey of an ancient amphorae workshop at Tsoukalia, Alonissos (Greece), Archaeol. Prospection, 9, 183-195.

Schiattarella, M., L. Ferranti, S.I. Giano and L. Maschio 
(1998): Evoluzione tettonica Quaternaria dell'alta Val d'Agri (Appennino Meridionale), in Riassunti $79^{\circ}$ Congresso SGI, 21-23 Settembre 1998, Palermo, 726-727.

SHARMA, P.S. (1997): Environmental and Engineering Geophysics (Cambridge Univ. Press), pp. 499.

TABBAGH, J. (1999): Filtrage numérique des donnes géophysiques, in Non-destructive Techniques Applied to Landscape Archaeology, edited by M. PASQUINUCCI and F. TRÉMENT (Oxbow Books, Oxford), pp. 276.

WitTen, A.J., T.E. LeVy, R.B. AdAMS and I.J. WON (2000): Geophysical surveys in the Jebel Hamrat Fidan, Jordan, Geoarchaeology, 15, 135-150.

(received January 30, 2004; accepted July 2, 2004) 